Portland State University

PDXScholar

$4-30-2021$

\title{
Density of Free-Roaming Cats Related to Feeding Stations on Hayden Island, Oregon
}

\author{
Olivia Helback \\ Portland State University \\ Joe Liebezeit \\ Portland Audubon
}

Follow this and additional works at: https://pdxscholar.library.pdx.edu/honorstheses

Part of the Other Animal Sciences Commons, and the Population Biology Commons Let us know how access to this document benefits you.

\section{Recommended Citation}

Helback, Olivia and Liebezeit, Joe, "Density of Free-Roaming Cats Related to Feeding Stations on Hayden Island, Oregon" (2021). University Honors Theses. Paper 981.

https://doi.org/10.15760/honors.1005

This Thesis is brought to you for free and open access. It has been accepted for inclusion in University Honors Theses by an authorized administrator of PDXScholar. Please contact us if we can make this document more accessible: pdxscholar@pdx.edu. 
Density of Free-Roaming Cats Related to Feeding Stations on Hayden Island, Oregon

\author{
Olivia Helback, Joe Liebezeit
}

\begin{abstract}
:
Free-roaming cats have a devastating impact on wildlife populations with stray/feral cats being the most problematic. In some areas, community members provide these cats with food, water, and shelter often in conjunction with a trap, neuter, return (TNR) program. Hayden Island located north of Portland, Oregon is home to a managed colony of feral and stray cats. Some island residents provide feeding stations for the cats and actively participate in population management. To determine how feeding stations might affect cat spatial distribution, camera traps were placed at 19 different stations in urban and natural areas on Hayden island. Additional annual road cat count data was used to compare cat density relative to feeding stations utilizing ArcGIS. When individual cat locations were overlapped with the heat map for feeding stations, greater cat densities in proximity to feeding stations were observed. These results were supported by a density analysis of cats and feeding stations as well as the camera trap results as only a single cat was photographed in the natural area. We documented that a reliable food source was connected to a higher density of cats in urban areas with less wildlife value and where they can be more easily monitored.
\end{abstract}




\section{Introduction:}

In 2019, a landmark study concluded that the population of North American birds had declined by around 3 billion in the last 50 years. (Rosenberg et al., 2019). The study represents only one of many concerning a recent loss of biodiversity associated with human-caused factors (Ceballos et al., 2013). Many concerned scientists and conservation groups to have begun to sound an alarm warning that if unless humanity changes our interactions with nature, we risk catastrophic loss. While most studies focus on direct human factors such as deforestation or climate change, one of the more controversial and indirect causes is predation by domestic cats.

It has been estimated that cats kill approximately 1.3-4 billion birds annually along with a staggering 6.3-22.3 billion mammals (Loss et al., 2013). While there have been various campaigns encouraging cat owners to keep their pet cats inside or using a collar with a bell, the most problematic population is stray and feral cats. Stray cats are cats that were owned in the past and are socialized to humans. Feral cats in contrast have had little to no human contact in their lives and are essentially wild. Both groups live exclusively outside and may not have access to food which makes them more liable to hunt wildlife. According to a study by Loss et al., (2013) stray and feral cats account for the majority of wildlife killed by cats in the U.S and Europe killing approximately 1,652 million birds a year and 10,903 million mammals a year. The study excluded reptiles, amphibians, and invertebrates making it a conservative estimate of the total ecological impact by stray and feral cats.

Despite the environmental danger cats pose, they are still considered domestic animals which makes their welfare important to animal advocacy groups and the public. In communities with large populations of stray and feral cats, community members often take it upon themselves to become cat caregivers by providing food, water, and shelter to the cats. Many conservationists 
argue that providing cats with resources allows them to live longer, produce more offspring, and therefore kill more wildlife (Maeda et al., 2019).

However, a variety of studies looking at the population dynamics of cats in mixed natural-urban areas have found that cat density is highest around feeding stations (Tennant and Downs 2008, Hernandez et al., 2018, Li et al., 2020). This is beneficial as it can be used to encourage cats to stay in areas of lower wildlife value. On the campus of University of KwaZulu-Natal's Howard College, a combined effort of road cat counts and GPS collars found that cat density was highest near the various feeding stations around campus while no cats were observed in the nearby Msinsi Nature Reserve (Tennant and Downs, 2008). While feedings stations may help to alter cat density, the lack of population management means the colony will continue to grow.

This dynamic could be altered with the addition of TNR. TNR stands for "Trap, Neuter, Return" and has become popular in recent years as a humane method to decrease the number of stray and feral cats. While each program is slightly different, the basis of TNR is that the cats are trapped, spayed or neutered to prevent further reproduction, and then released back in the area they were trapped. (Trap-Neuter-Return-Feral Cat Coalition 2020, Wolf et al. 2019) A study on the use of TNR and feeding stations to manage a cat colony on an Australian campus noted that the congregation of cats around feeding stations allowed volunteer caretakers to better monitor the cats. Volunteers used the daily feedings as a way to estimate population size, identify immigrant cats, and administer medicine (Swarbrick and Rand, 2018). Modeling studies suggest that in order for cat populations to decline under a sterilization program like TNR, $75 \%$ of the population must be sterilized (Anderson et al., 2004). Using feeding stations to create areas of high cat density could help achieve this. 
Our area of study is Hayden Island, located in the Columbia River just south of the Washington border. It is home to a free-roaming cat colony of an estimated 322-537 cats (Cove et al., unpublished data 2019). A population management program has been in effect since 2014 and utilizes TNR, cat adoption, and public education to reduce the cat population on the island. These efforts have been centered around the manufactured home communities and RV parks around the island. Some residents in these areas are caregivers and have feeding stations for the cats. Based on annual cat counts, these areas also have the highest density of cats (Unpublished data, Portland Audubon). Additionally, a recent study on the island used stable isotope testing to determine that on average $67 \%$ of the stray and feral cat diet consisted of commercial dry cat food provided by residents (Cove et al., unpublished data 2019). The isotope analysis demonstrates that at least some of the stray and feral cats depend on the feeding stations as a primary source of food.

Assuming cats tend to stay near areas where they have a reliable food source, does the presence of feeding stations discourage cats from entering the natural area? This paper will examine the cat density based on 2019 road survey of a managed cat colony on Hayden Island. Based on evidence from the cat counts and isotope data, we predict there will be a positive correlation between cat density and feeding station density and significantly fewer cats in the natural area. 


\section{Materials and Methods:}

\section{Study Area:}

The study site, Hayden Island, is located in the Columbia River on the border between Oregon and Washington. Hayden Island is approximately $1.7 \mathrm{mi}^{2}$ and has a population of approximately 2,500. This study focused on two areas on Hayden Island: the manufactured home community and the natural area (fig 1). The manufactured home community consists of mobile home communities and RV parks. The natural area covers approximately half the island and is undeveloped land owned by the Port of Portland. It consists of bottomland hardwood forest, wetlands, and open clearings where species such as deer, coyotes, and raccoons have been recorded (West Hayden Island, n.d.). Both areas on the island possess a temperate oceanic climate with an average rainfall of 36 inches (Climate Portland - Oregon and Weather Averages Portland, n.d.).

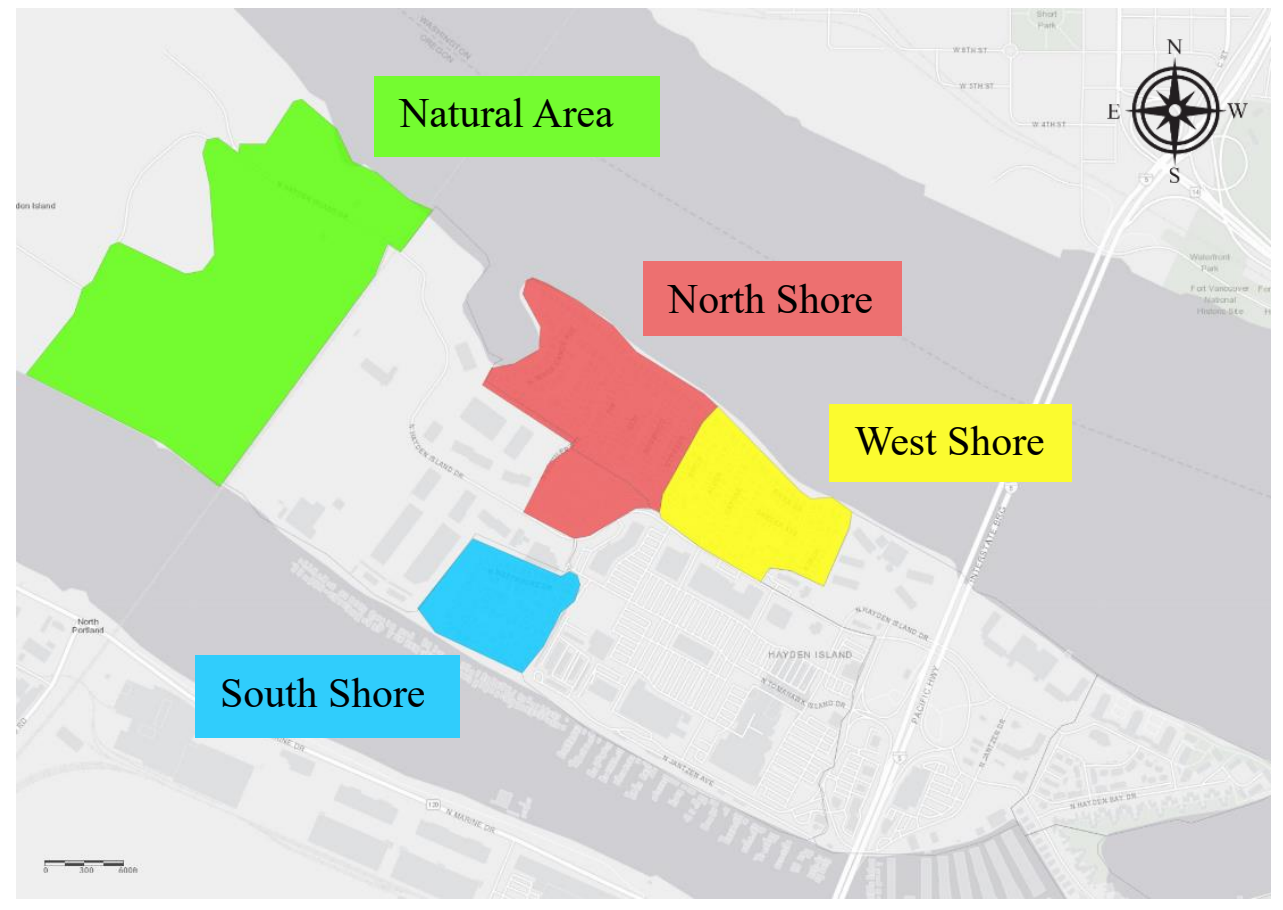

Figure 1: Map of Hayden Island outlining the four survey zones. 


\section{Camera Trap Study:}

For the purpose of the study, the island was divided into four zones (Fig 1). Three zones in the manufactured home community, and one zone consisting of the natural area. Five cameras total were deployed, three Browning cameras (Browning Strike Force HD Pro) with cases and two Bushnell cameras (Bushnell Aggressor Trophy Cam HD). Each camera was placed on the same settings for consistency (capture mode: still images; capture delay: 5 seconds; picture size: 4 or $5 \mathrm{MP}$; photos/trigger: 5; date and time stamp: on). Cameras were mounted with a view of an identified wildlife corridor in order to capture side profiles for easy identification. Each camera trap was retrieved after one week and moved to a new location for a total of 15 surveyed locations in the residential zones (Fig 2). In the natural area, four camera traps were set up with identical settings to the residential cameras and were left out for a total of three weeks.

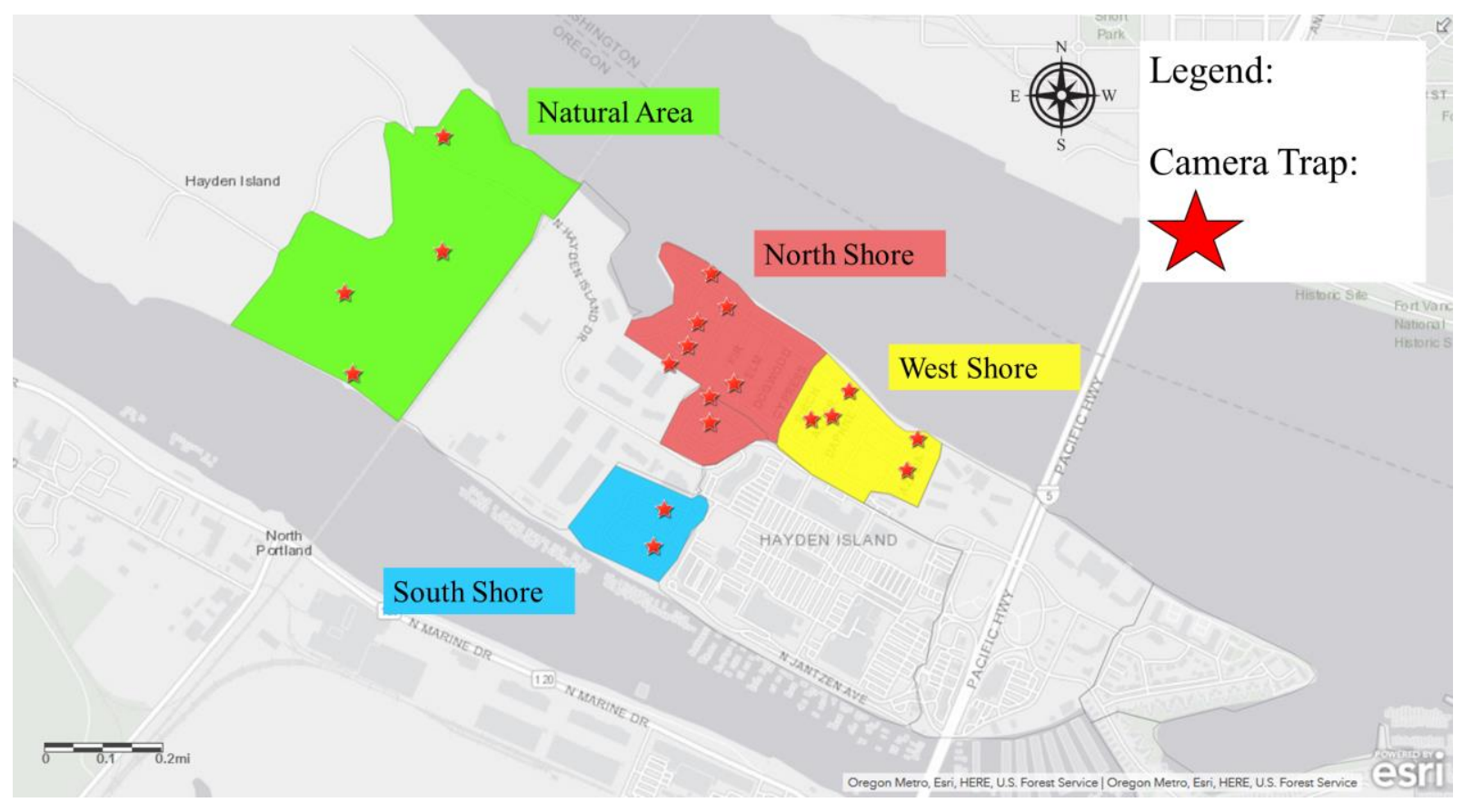

Figure 2: Labeled survey zones with camera post locations. 


\section{Cat Count and Feeding Station Data:}

Data from the 2019 road cat count and a 2015 survey of community member run feeding stations was obtained from Portland Audubon. This data consisted of the GPS coordinates of all cats observed during the count which occurs in the residential area of the island as well as the GPS coordinates of community member reported feeding stations. The exact coordinates of the feeding stations and caregiver houses were not reported due to a privacy agreement made with the individuals surveyed. The cat location coordinates were visualized in ArcGIS and overlaid with a heatmap of the feeding station density.

\section{Results:}

\section{Camera Trap Study Results:}

All cats identified as unique individuals from the camera trap images were given an identification number and marked as either having a collar (owned pet cat), possessing a tipped ear (a stray or feral cat having gone through the TNR process), or neither. A total of 38 individuals were identified with 37 recorded in the residential zones. Only a single individual was recorded in the natural area. The same individual was also identified in a 2018 camera trap analysis of the natural area suggesting there is minimal migration of cats to the natural area (Liebezeit, unpublished data 2018-19). This cat has not been documented outside of the natural area although the cat is ear-tipped suggesting that it moved from the populated area of the island to the natural area. 


\section{Cat Count Data:}

The heat map data generated in ArcGIS showed a clear overlap in the areas of highest cat density and highest feeding station density (Fig 3). Additionally, the density of feeding stations positively correlated to the density of cats based on a linear regression analysis (Fig 4).

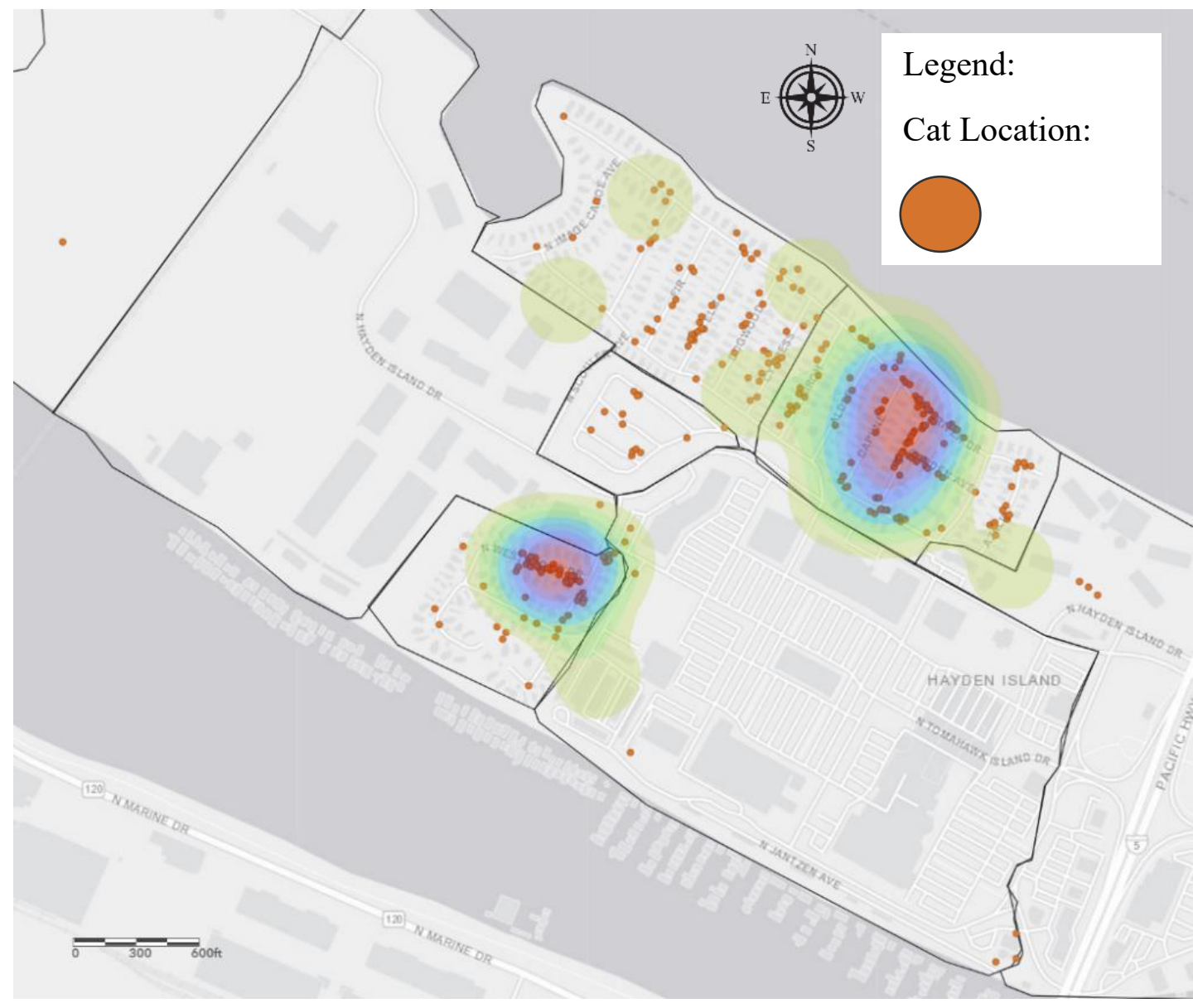

Figure 3: The coordinates of cats from the road count overlaid with the density map for feeding stations. 


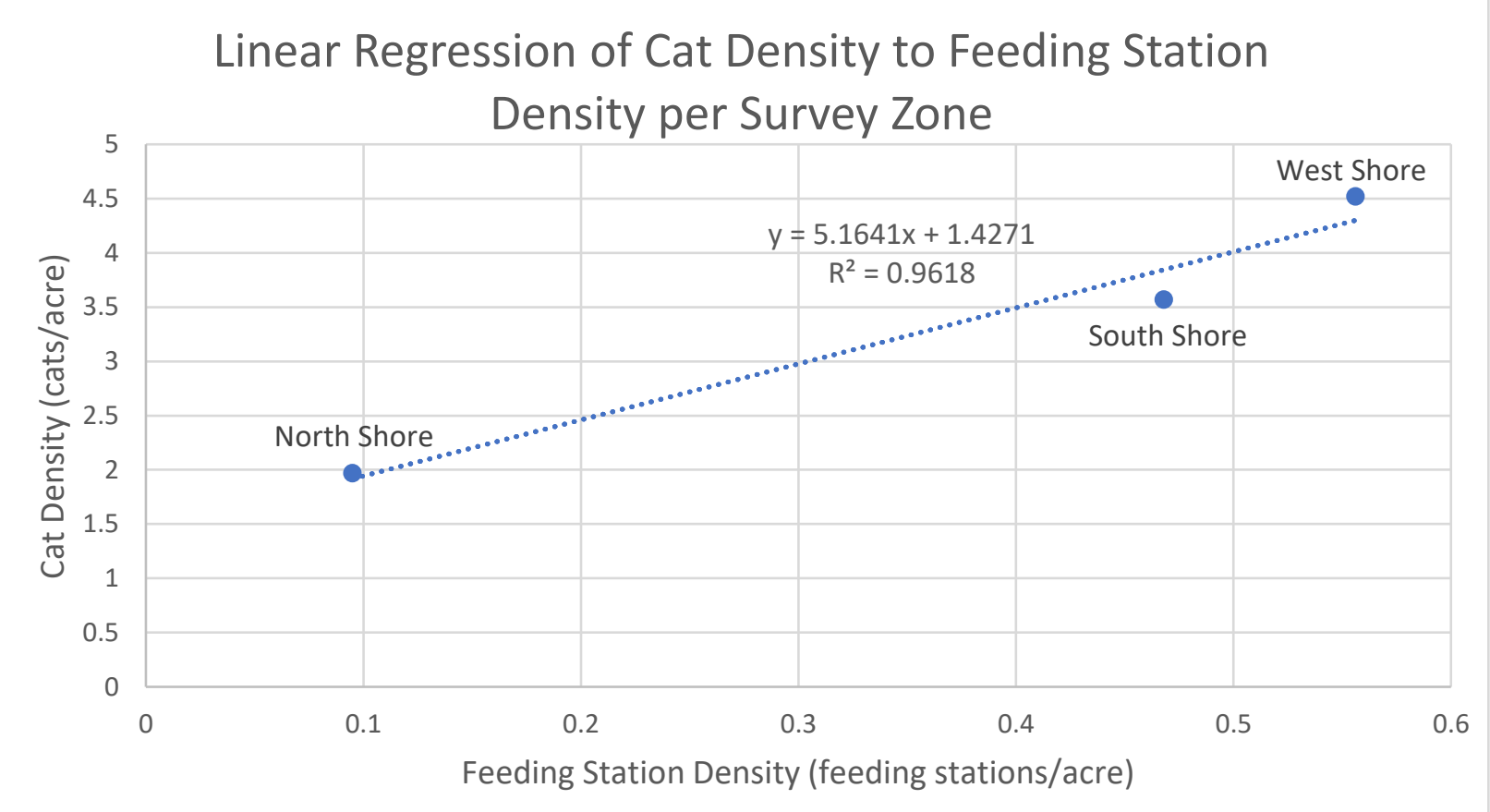

Figure 4: Linear regression of cat density based on feeding station density in the manufacture home community zones.

\section{Discussion:}

The data supports the hypothesis that cat density is related to feeding station density as cats are drawn to a constant food source. This is not coincidental as a stable isotope analysis performed on free-roaming cats on the island showed that on average, $67 \%$ of their diet consisted of the dry cat food provided at feeding stations (Cove et al., unpublished data 2018-19). This demonstrates that the cats are using the feeding stations and seem to prefer the dry food to eating wildlife. Additionally, only one cat was recorded in the natural area. This individual cat was also recorded in the natural area in a 2018 camera trap effort. (Liebezeit, unpublished data 2018-19). This suggests that this individual is an outlier and that most cats tend to stay in the urban areas where there is less wildlife value. This pattern has been shown in other studies documenting cat 
density in an urban landscape with nearby natural areas such as the study at the University of KwaZulu-Natal's Howard College mentioned earlier. Throughout the study period, no cats were observed in the natural area and cat density increased around feeding stations. A sub-group of cats in the study were fitted with radio collars and it was determined their home ranges tended to overlap with one or multiple feeding stations (Tennent and Downs, 2008).

There is even support that feeding stations can alter cat activity patterns. A study by Hernandez et al. (2018) placed camera collars on stray cats in a managed colony provided with food at designated feeding stations on Jekyll Island, Georgia. Based on the camera data, they determined that cats spent on average $89.5 \%$ of the time on video sleeping or resting and only $0.9 \%$ percent of the time on average hunting. In contrast, a similar study that monitored activity in feral cats that had no human interaction and were not fed reported $14 \%$ of the time spent running and/or hunting (Horn et al., 2011).

While feeding stations may be one factor in the high density of cats in the residential zones, coyotes were documented in the natural area in both the 2018 and 2019 camera trap surveys (Liebezeit, unpublished data 2018-19). Coyotes have been shown to deter cats from entering natural areas (Gehrt et al. 2013). Coyotes will prey on cats and so cats tend to avoid areas with coyotes. It is possible the low cat density in the natural area is due to coyotes, not the feeding stations. However, since the feeding station density was positively correlated with cat density even in the urban areas (Fig 4) where coyotes were not present, it is likely a mix of both factors.

Additionally, the feeding station coordinates are from 2015 meaning it is possible certain feeding stations could no longer be present or moved. Even if this were the case, the data 
strongly suggest that any new feeding stations would still overlap with the highest density of cats.

Important to note is that feeding alone is not a valid solution to cat colonies. Feeding cats can lead to increased cat density around feeding stations which increases breeding opportunities if cats are not desexed. It can also increase the chance for disease transmission if the cats have not been properly vaccinated (Hernandez et al., 2018). Feeding stations paired with a population management solution such as TNR in conjunction with adoptions of socialized cats and vaccinations for cats to be released back into the community are the most viable solution for both decreasing wildlife predation, and humanely eliminating cat colonies. However, this solution is only feasible in an area with a large low-density urban space where cats can interact with humans. In certain areas where cat populations have no human contact, feeding stations will likely have less of an impact on decreasing wildlife predation by cats. Eliminating cat colonies via TNR or a similar program can take up to several decades depending on the intensity of the program and initial number of cats (Spehar and Wolf 2017, Spehar and Wolf 2019). In environments with a large number of endemic species and high wildlife values, such a solution may not be feasible due to concerns about rapidly declining native species populations (Crawford et al., 2019). This is also a concern in areas that act as breeding grounds for vulnerable populations (Greenwell et al., 2019).

Future work should consist of more tracking efforts via radio or GPS collars to determine how and where feral and stray cats spend their time. On-going research into non-surgical sterilization methods could make feeding stations a direct site of TNR via a pill or injection that renders the cat sterile. For now, TNR and feeding stations used tactfully are the best chance of humanely decreasing cat populations. 


\section{Conclusion:}

Despite wariness about purposefully feeding stray and feral cats, our results indicate that feeding stations placed in areas of lower wildlife value can keep cats concentrated in those areas and away from more sensitive wildlife areas. Feeding stations can also alter cat behavior resulting in less time on average spent hunting and allowing for better monitoring and implementation of population management techniques such as TNR.

However, regardless of ownership, free-roaming cats pose a threat to wildlife and are at a higher risk of injury, illness, and death (Crawford et al., 2019). The end goal for any stray and feral cat colony should be elimination via humane programs such as adoptions and TNR. The use of feeding stations to alter cat spatial density is merely a tool in the ongoing effort to manage free-roaming cats and should not be considered as a method to completely eliminate predation by cats. By better understanding cat population dynamics and behavior, conservationists and animal advocates alike stand a better chance of reducing the number of cats in the environment in a safe and humane way. 


\section{Literature Cited:}

Andersen, M., Martin, B., Roemer, G., 2004. Use of matrix population models to estimate the efficacy of euthanasia versus trap-neuter-return for management of free-roaming cats. Journal of the American Veterinary Medical Association. 225, 1871-1876.

Ceballos, G., Ehrlich, P.R., Barnosky, A. D., García, A., Pringle, R.M., Palmer, T., 2015. Accelerated modern human-induced species losses: Entering the sixth mass extinction. Science Advances. 1, e1400253.

Climate Portland—Oregon and Weather averages Portland. (n.d.). Retrieved February 5, 2020, from https://www.usclimatedata.com/climate/portland/oregon/united-states/usor0275

Crawford, H.M., Calver, M.C., Fleming, P.A., 2019. A Case of Letting the Cat out of The BagWhy Trap-Neuter-Return Is Not an Ethical Solution for Stray Cat (Felis catus) Management. Animals. 9, 171-171.

Gehrt, S.D., Wilson, E.C., Brown, J.L., Anchor, C., 2013. Population Ecology of Free-Roaming Cats and Interference Competition by Coyotes in Urban Parks. PLOS ONE. 8, e75718.

Greenwell, C.N., Calver, M.C., Loneragan, N.R., 2019. Cat Gets Its Tern: A Case Study of Predation on a Threatened Coastal Seabird. Animals. 9, 445-445. 
Hernandez, S.M., Loyd, K.A., Newton, A.N., Gallagher, M., Carswell, B.L., Abernathy, K. J., 2018. Activity patterns and interspecific interactions of free-roaming, domestic cats in managed Trap-Neuter-Return colonies. Applied Animal Behaviour Science. 202, 63-68.

Horn, J.A., Mateus-Pinilla, N., Warner, R.E., Heske, E.J., 2011. Home range, habitat use, and activity patterns of free-roaming domestic cats. The Journal of Wildlife Management. 75, $1177-1185$.

Li, Y., Wan, Y., Zhang, Y., Gong, Z., Li, Z., 2020. Understanding how free-ranging cats interact with humans: A case study in China with management implications. Biological Conservation. 249, 108690.

Loss, S. R., Will, T., Marra, P.P., 2013. The impact of free-ranging domestic cats on wildlife of the United States. Nature Communications. 4, 1396.

Maeda, T., Nakashita, R., Shionosaki, K., Yamada, F., Watari, Y., 2019. Predation on endangered species by human-subsidized domestic cats on Tokunoshima Island. Scientific Reports. 9, 16200.

Rosenberg, K.V., Dokter, A.M., Blancher, P.J., Sauer, J.R., Smith, A.C., Smith, P.A., Stanton, J.C., Panjabi, A., Helft, L., Parr, M., Marra, P.P., 2019. Decline of the North American avifauna. Science, 366, 120-124. 
Spehar, D.D., Wolf, P.J., 2019. Back to School: An Updated Evaluation of the Effectiveness of a Long-Term Trap-Neuter-Return Program on a University's Free-Roaming Cat Population. Animals. 9, 768.

Swarbrick, H., Rand, J., 2018. Application of a Protocol Based on Trap-Neuter-Return (TNR) to Manage Unowned Urban Cats on an Australian University Campus. Animals, 8(5), 77.

Tennent, J., Downs, C.T., 2008. Abundance and Home Ranges of Feral Cats in an Urban Conservancy Where There Is Supplemental Feeding: A Case Study from South Africa.” African Zoology. 43, 218-29.

West Hayden Island. (n.d.). Portland Audubon. Retrieved March 17, 2021, from https://audubonportland.org/our-work/protect/habitat-and-wildlife/urban/protecting-andrestoring-our-urban-rivers/west-hayden-island/

Wolf, P.J., Rand, J., Swarbrick, H., Spehar, D.D., Norris, J., 2019. Reply to Crawford et al.: Why Trap-Neuter-Return (TNR) Is an Ethical Solution for Stray Cat Management. Animals. 9, 689-689. 